Article

\title{
Biomarkers of Micronutrients in Regular Follow-Up for Tyrosinemia Type 1 and Phenylketonuria Patients
}

\author{
Kimber van Vliet ${ }^{1}$, Iris L. Rodenburg ${ }^{1}$, Willem G. van Ginkel ${ }^{1}$, Charlotte M.A. Lubout ${ }^{1}$, \\ Bruce H.R. Wolffenbuttel ${ }^{2}$, Melanie M. van der Klauw ${ }^{2}$, M. Rebecca Heiner-Fokkema ${ }^{3}$ and \\ Francjan J. van Spronsen ${ }^{1, *}$ \\ 1 Division of Metabolic Diseases, Groningen, Beatrix Children's Hospital, University Medical Center \\ Groningen, University of Groningen, 9700 RB Groningen, The Netherlands \\ 2 Department of Endocrinology, Groningen, University Medical Center Groningen, University of Groningen, \\ 9700 RB Groningen, The Netherlands \\ 3 Laboratory of Metabolic Diseases, Groningen, Department of Laboratory Medicine, University Medical \\ Center Groningen, University of Groningen, 9700 RB Groningen, The Netherlands \\ * Correspondence: f.j.van.spronsen@umcg.nl; Tel.: +31-50-361-1036
}

Received: 17 July 2019; Accepted: 21 August 2019; Published: 27 August 2019

\begin{abstract}
Phenylketonuria (PKU) is treated with dietary restrictions and sometimes tetrahydrobiopterin (BH4). PKU patients are at risk for developing micronutrient deficiencies, such as vitamin B12 and folic acid, likely due to their diet. Tyrosinemia type 1 (TT1) is similar to PKU in both pathogenesis and treatment. TT1 patients follow a similar diet, but nutritional deficiencies have not been investigated yet. In this retrospective study, biomarkers of micronutrients in TT1 and PKU patients were investigated and outcomes were correlated to dietary intake and anthropometric measurements from regular follow-up measurements from patients attending the outpatient clinic. Data was analyzed using Kruskal-Wallis, Fisher's exact and Spearman correlation tests. Furthermore, descriptive data were used. Overall, similar results for TT1 and PKU patients (with and without BH4) were observed. In all groups high vitamin B12 concentrations were seen rather than B12 deficiencies. Furthermore, all groups showed biochemical evidence of vitamin D deficiency. This study shows that micronutrients in TT1 and PKU patients are similar and often within the normal ranges and that vitamin D concentrations could be optimized.
\end{abstract}

Keywords: Phenylketonuria; Tyrosinemia type 1; nutritional status; micronutrients; vitamin D; vitamin B12

\section{Introduction}

Phenylketonuria (PKU, OMIM 261600) and tyrosinemia type 1 (TT1, OMIM 276700) are both inborn errors affecting the phenylalanine-tyrosine degradation pathway necessitating a comparable dietary treatment. PKU affects approximately 1:18.000 newborns and is caused by a defect in the enzyme phenylalanine hydroxylase. Biochemically, this leads to high phenylalanine and low/normal tyrosine concentrations. Untreated, high phenylalanine concentrations will lead to severe mental impairments [1]. Treatment nowadays consists of dietary restriction of phenylalanine, amino acid supplements, and, if patients are responsive, the drug sapropterin dihydrochloride, which is the synthetic form of tetrahydrobiopterin (BH4) [2]. BH4 acts as a pharmacological chaperone of phenylalanine hydroxylase, improving the conversion of phenylalanine into tyrosine, thereby lowering the phenylalanine concentrations [3]. Various studies have been conducted on the effect of this dietary treatment and of $\mathrm{BH} 4$ on the nutritional and biochemical parameters in PKU, reporting that PKU patients are at risk for micronutrient deficiencies such as vitamin B12, folic acid, selenium, zinc and 
iron [4-6]. This also applies to PKU patients who are treated with BH4, in whom deficiencies may result from their liberalized diet [7-9].

Tyrosinemia type 1 is caused by a deficiency of the enzyme fumarylacetoacetate hydrolase and is much rarer than PKU, affecting approximately 1:100.000 newborns. The deficient enzyme leads to the accumulation of toxic metabolites, which in turn cause renal tubular dysfunction, neurological porphyria-like crises, liver failure and liver cancer [10]. In the past, the only definitive form of treatment was a liver transplantation, usually at a very young age, in order to survive. Since 1992, however, a new treatment option has become available called 2-(2-nitro-4-trifluoromethylbenyol)-1,3-cyclohexanedione (NTBC), which blocks the activity of 4-hydroxyphenylpyruvate dioxygenase, an enzyme upstream of the metabolic defect [11]. Treatment nowadays consists of NTBC paired with a dietary restriction of tyrosine and its precursor phenylalanine. On this treatment, outcome has improved tremendously. Since the NTBC-dietary treatment, the focus of research has shifted towards neurocognitive deficits that are observed and their possible cause [12-16]. At present, however, little research has been conducted on the nutritional and biochemical parameters in TT1. Although PKU and TT1 are different diseases, they are treated with a comparable protein-restricted diet and amino acid supplements. This raised the question whether TT1 patients may also be at risk for micronutrient deficiencies as in PKU patients.

Therefore, the aim of this retrospective study was (1) to compare outcomes of regular biochemical follow-up measurements of TT1 and PKU patients (both with and without BH4 treatment); (2) to investigate possible deficiencies or excesses in blood of TT1 patients, PKU patients treated with BH4 (PKU-BH4), and PKU patients not treated with BH4 (PKU-nBH4); and (3) to assess possible correlations between dietary intake and metabolic control and these regular follow-up outcomes.

\section{Materials and Methods}

\subsection{Participants}

In total, 12 TT1 patients (mean age $13.5 \pm 9.9,75 \%$ male) and 92 PKU patients (mean age $24.5 \pm 13.9$, $45 \%$ male) were included. All patients were treated at the University Medical Center Groningen, The Netherlands. Of the PKU patients, 33 patients (36\%) received $\mathrm{BH} 4$ at the time of assessment. BH4 dosages ranged from $100 \mathrm{mg}$ to $1400 \mathrm{mg}$ a day. The TT1 patients were all treated with NTBC and dietary restriction of phenylalanine and tyrosine. NTBC dosages ranged from $0.51 \mathrm{mg} / \mathrm{kg} / \mathrm{day}$ to $1.17 \mathrm{mg} / \mathrm{kg} / \mathrm{day}$. Both the TT1 and PKU patient groups were treated with several different amino acid mixtures (see Supplementary Material S1 for information regarding micronutrient and mineral content of amino acid supplements used by our patients). The need for formal ethical review and informed consent was waived by the local medical ethical committee.

\subsection{Study Parameters}

Data were collected retrospectively from patient files. From each patient the most recent blood measurements at the outpatient clinic for regular follow-up were included. All data came from blood samples collected between 14 August 2017 and 29 April 2019. Patients who had no blood samples taken at the hospital in that period were excluded from analyses. Concentrations were considered abnormal if they were found to be outside the reference range of the hospital laboratory information system.

All blood measurements during regular outpatient clinic visits were collected, which encompassed: leucocytes, hemoglobin $(\mathrm{Hb})$, hematocrit $(\mathrm{Ht})$, mean corpuscular volume $(\mathrm{MCV})$, thrombocytes, plasma sodium, potassium, chloride, creatinine, urea, calcium, phosphate, magnesium, albumin, total protein, alkaline phosphatase, ferritin, vitamin B12, methylmalonic acid (MMA), total homocysteine, 25-OH-vitamin D3, pre albumin, and thyroid stimulating hormone (TSH). Furthermore, plasma phenylalanine and tyrosine concentrations were collected. Plasma folic acid, alanine aminotransferase and aspartate aminotransferase concentrations were excluded from analyses, as folic acid concentrations were in the majority of cases derived from hemolytic blood samples, which can give falsely elevated results, and alanine aminotransferase and aspartate aminotransferase were only occasionally collected. 
For the remaining blood parameters, in total, $17 \%$ of our blood value data were missing. From the day of blood collection, the standard deviation scores (sds) of anthropometric measurements (height sds, weight sds, and body mass index (BMI) sds) were collected, as well as dietary information, which included total protein intake, natural protein intake, protein intake from amino acid supplements and total protein intake per kg body weight.

\subsection{Statistical Analyses}

Differences in anthropometric measurements and dietary intake between the groups were investigated using Kruskal-Wallis tests, since data were not normally distributed. The Mann-Whitney $\mathrm{U}$ test was used as a post-hoc test, and its $p$-value was corrected for multiple comparisons according to Bonferroni. Since some reference values from the blood measurements differed between age and gender, categorical variables were created (below normal, normal, and above normal). Because of the low expected cell frequencies for these measurements, Fisher's exact tests were performed to determine differences between TT1, PKU-nBH4 and PKU-BH4 patients and 2-sided $p$-values were adhered. Additionally, percentages of these abnormal values were calculated.

To investigate possible correlations between outcomes and dietary intake, Spearman correlation tests were performed. Since dietary intake differs between age groups, the percentage of natural protein intake from total protein intake was calculated and used for these analyses. Lastly, Spearman tests were used for investigating possible correlations between metabolic control (phenylalanine and tyrosine concentrations) and observed deficiencies and/or excesses. All statistical analyses were performed using IBM SPSS Statistics 23. $p$-values $<0.05$ were considered statistically significant.

\section{Results}

\subsection{Tyrosinemia Type 1 (TT1) versus Phenylketonuria (PKU)-nBH4 versus PKU-BH4}

Descriptives are summarized in Table 1. No significant differences were observed between the groups regarding the anthropometric measurements. When comparing percentage of natural protein intake between the three patient groups, Kruskal-Wallis tests showed a significant difference $(p<0.001)$. Pairwise comparisons then showed that differences existed between PKU-BH4 and PKU-nBH4 patients $(p<0.001)$ and between TT1 and PKU-BH4 patients $(p=0.033)$, with higher natural protein intake for PKU-BH4 patients, as expected. After Bonferroni correction for multiple comparisons only the difference between PKU-BH4 and PKU-nBH4 remained statistically significant $(p<0.001)$.

To investigate differences in blood measurements between the patient groups (TT1, PKU-nBH4, or PKU-nBH4) Fisher's exact tests were performed using the categorical data. A significant difference between the groups was observed regarding MCV levels $(p=0.038)$, suggesting more often higher MCV levels in the PKU-BH4 group compared to the TT1 and PKU-nBH4 groups. Other than this, no significant differences between the three groups were observed. 
Table 1. Descriptive data. For each patient group the minimum and maximum observed values were included, as well as the number of patients for which that value was collected.

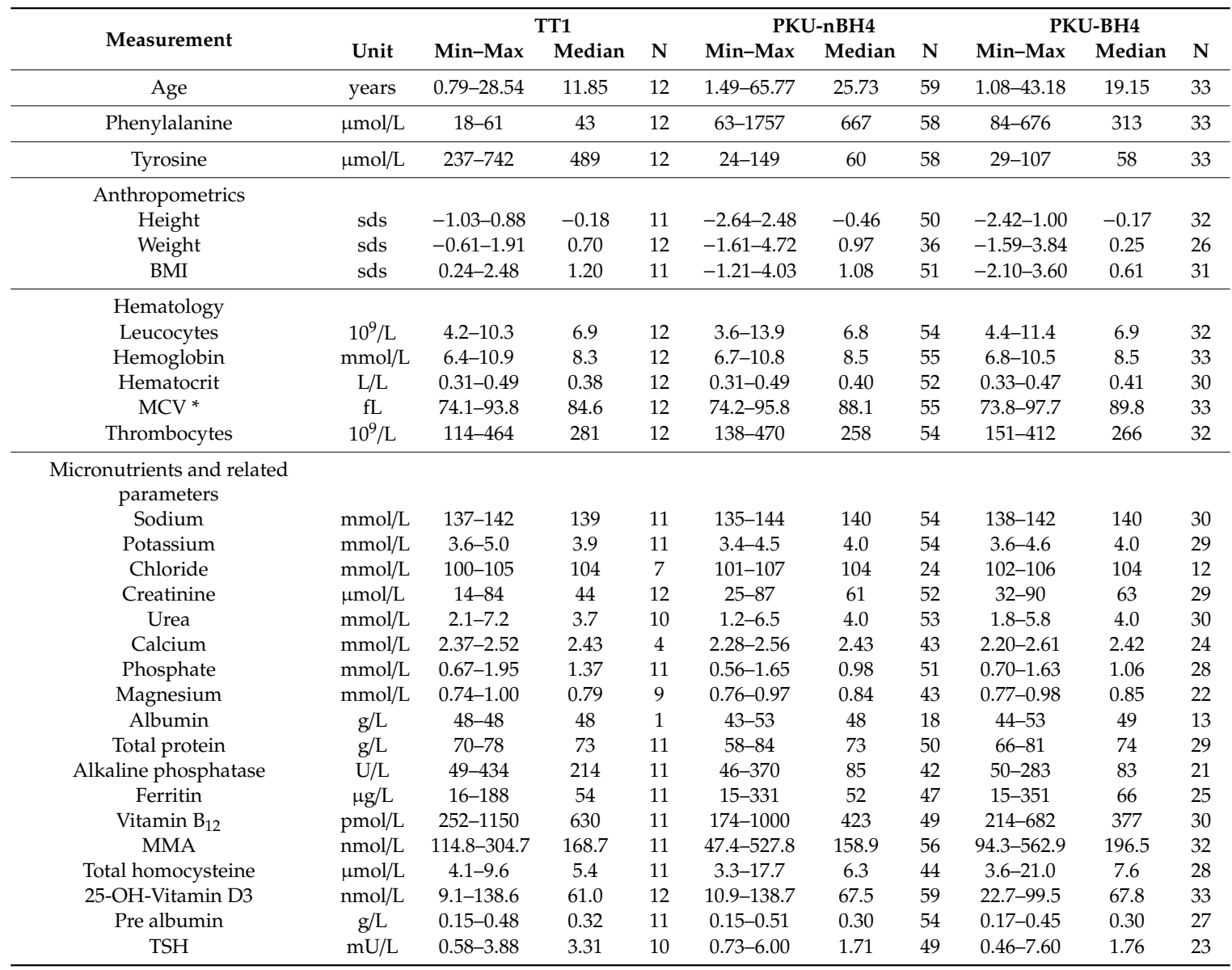

Abbreviations: TT1 = Tyrosinemia type 1; PKU = Phenylketonuria; Sds = standard deviation scores; BMI = body mass index; $\mathrm{MCV}=$ mean corpuscular volume; $\mathrm{MMA}=$ methylmalonic acid; TSH = thyroid stimulating hormone.

* Significant difference between all groups with $p<0.05$ (Fisher's exact test).

\subsection{Deficiencies or Excesses}

Table 2 shows percentages of patients with values below or above the reference ranges in the different patient groups (TT1, PKU-BH4, and PKU-nBH4). High vitamin B12 concentrations were often observed (Figure 1). All patient groups appeared to be prone to having an excess of vitamin B12, with respectively $36 \%, 33 \%$ and $20 \%$ of the patients having a concentration above the reference limit. Elevated levels of MMA and total homocysteine were occasionally observed (in 5 and 2 patients respectively). Elevation was always in only one of these markers, never in both.

Next to this, low vitamin D concentrations were present in our sample (Figure 1). This was the case for all patient groups, and especially for both groups of PKU patients $(8 \%, 29 \%$, and $24 \%$ respectively). Since vitamin D levels are known to differ depending on time of the year [17], Figure 2 shows the vitamin D concentrations observed per month. 
Table 2. Percentage of patients within the different patient groups with too low/deficient blood concentrations, and too high/excessive concentrations. Percentages are included when the $\mathrm{N}>0$.

\begin{tabular}{ccccccc}
\hline & \multicolumn{2}{c}{ Patients with a Deficiency } & \multicolumn{2}{c}{ Patients with an Excess } \\
\hline & TT1 & PKU-nBH4 & PKU-BH4 & TT1 & PKU-nBH4 & PKU-BH4 \\
\hline & $\mathbf{N}$ & $\mathbf{N}$ & $\mathbf{N}$ & $\mathbf{N}$ & $\mathbf{N}$ & $\mathbf{N}$ \\
\hline Blood count & & & & & & \\
Leucocytes & $1(8 \%)$ & $2(4 \%)$ & 0 & 0 & $4(8 \%)$ & $3(9 \%)$ \\
Hemoglobin & 0 & $2(4 \%)$ & $1(3 \%)$ & 0 & 0 & 0 \\
Hematocrit & 0 & $1(2 \%)$ & 0 & $1(8 \%)$ & $3(6 \%)$ & $5(16 \%)$ \\
MCV & 0 & 0 & 0 & 0 & $1(2 \%)$ & $5(15 \%)$ \\
Thrombocytes & $1(8 \%)$ & $4(8 \%)$ & 0 & $2(17 \%)$ & $4(7 \%)$ & $2(6 \%)$ \\
\hline Micronutrients and related parameters & & & & & & \\
Sodium & 0 & 0 & 0 & 0 & 0 & 0 \\
Potassium & 0 & $2(4 \%)$ & 0 & 0 & 0 & 0 \\
Chloride & 0 & 0 & 0 & 0 & 0 & 0 \\
Creatinine & $1(8 \%)$ & $2(4 \%)$ & $1(3 \%)$ & 0 & 0 & 0 \\
Urea & 0 & $5(10 \%)$ & $1(3 \%)$ & 0 & 0 & 0 \\
Calcium & 0 & 0 & 0 & 0 & 0 & $1(4 \%)$ \\
Phosphate & $1(9 \%)$ & $2(4 \%)$ & $1(3 \%)$ & 0 & 0 & 0 \\
Magnesium & 0 & 0 & 0 & 0 & 0 & 0 \\
Albumin & 0 & 0 & 0 & 0 & $4(24 \%)$ & $3(23 \%)$ \\
Total protein & 0 & $1(2 \%)$ & 0 & 0 & $1(2 \%)$ & $3(10 \%)$ \\
Alkaline phosphatase & 0 & 0 & 0 & $1(9 \%)$ & $2(5 \%)$ & $1(5 \%)$ \\
Ferritin & 0 & $2(4 \%)$ & $2(8 \%)$ & 0 & $3(7 \%)$ & 0 \\
Vitamin B B & 0 & 0 & 0 & $4(36 \%)$ & $16(33 \%)$ & $6(20 \%)$ \\
MMA & 0 & $4(7 \%)$ & 0 & 0 & $2(4 \%)$ & $3(9 \%)$ \\
Total homocysteine & 0 & 0 & 0 & 0 & $1(2 \%)$ & $1(3 \%)$ \\
25-OH-Vitamin D3 & $1(8 \%)$ & $17(29 \%)$ & $8(24 \%)$ & 0 & 0 & 0 \\
Pre albumin & $1(9 \%)$ & $6(11 \%)$ & $1(4 \%)$ & $3(27 \%)$ & $4(8 \%)$ & $3(11 \%)$ \\
TSH & 0 & 0 & $1(4 \%)$ & 0 & $3(6 \%)$ & $1(4 \%)$ \\
\hline
\end{tabular}

Abbreviations: $\mathrm{TT} 1$ = Tyrosinemia type $1 ; \mathrm{PKU}=$ Phenylketonuria; $\mathrm{MCV}=$ mean corpuscular volume; MMA = methylmalonic acid; TSH $=$ thyroid stimulating hormone.
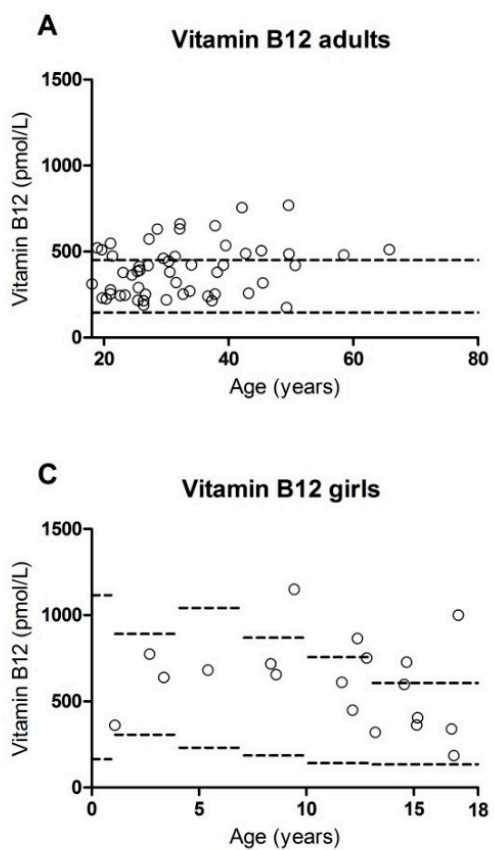
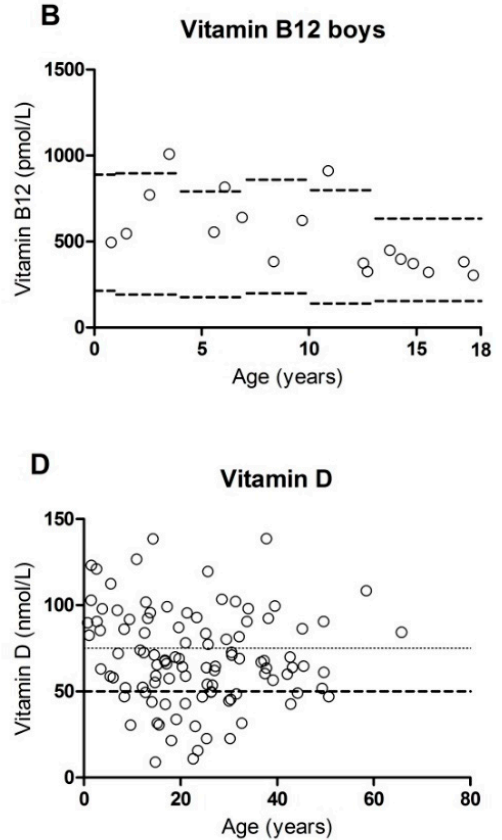

Figure 1. Distribution of vitamin concentrations in patients with reference ranges (depending on age). (A): Vitamin B12 concentrations in adult patients. (B): Vitamin B12 concentrations in male patients aged $<18$ years. (C): Vitamin B12 concentrations in female patients aged $<18$ years. (D): Vitamin D concentrations in patients with lower reference limit of $50 \mathrm{nmol} / \mathrm{L}$ and recommended limit of $75 \mathrm{nmol} / \mathrm{L}$. 


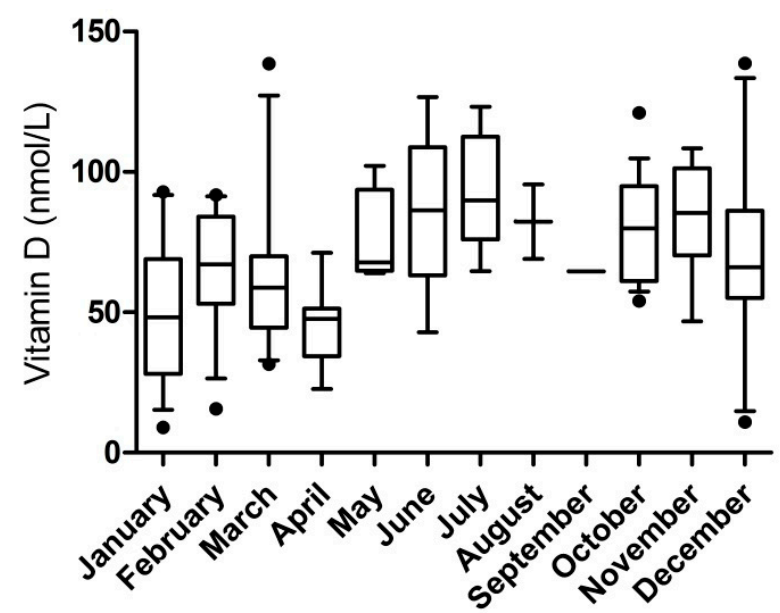

Figure 2. Vitamin D concentrations per month. Whiskers indicating 10-90 percentiles.

\subsection{Correlations with Dietary Intake}

When correlating the blood concentrations to the percentage of natural protein intake, correlations were observed for vitamin B12 $(r=-0.277, p=0.013)$, total homocysteine $(r=0.346, p=0.002)$, and vitamin $\mathrm{D}(\mathrm{r}=-0.232, p=0.026)$. These correlations suggest that vitamin $\mathrm{B} 12$ and $\mathrm{D}$ concentrations are lower in patients with a higher percentage of natural protein intake, and that total homocysteine concentrations are higher with more natural protein intake. No other correlations were observed between protein intake and blood concentrations.

\subsection{Correlations with Phenylalanine and Tyrosine Concentrations}

Spearman correlation tests were performed to investigate possible correlations between the vitamin B12 and vitamin D concentrations and phenylalanine and tyrosine concentrations. Separate analyses were performed for TT1 and PKU patients because of the opposite biochemical profile. For TT1 a significant correlation was observed between tyrosine and vitamin B12 $(r=-0.627, p=0.039)$ and a trend was observed for tyrosine and vitamin $\mathrm{D}(\mathrm{r}=-0.566, p=0.055)$. For PKU patients significant positive correlations were observed between tyrosine concentrations and both vitamin B12 $(r=0.279$, $p=0.013)$ and vitamin $\mathrm{D}(\mathrm{r}=0.319, p=0.002)$. Phenylalanine concentrations showed no significant correlations in neither the TT1 or the PKU group.

When investigating PKU-nBH4 and PKU-BH4 patients separately, PKU-BH4 patients showed no significant correlations. PKU-nBH4 patients showed a significant correlation between tyrosine and vitamin $\mathrm{D}(\mathrm{r}=0.378, p=0.003)$. Furthermore, trends were observed between tyrosine concentrations and vitamin $\mathrm{B} 12(\mathrm{r}=0.272, p=0.061)$ and between phenylalanine and vitamin $\mathrm{D}(\mathrm{r}=-0.255, p=0.054)$.

\section{Discussion}

This study describes micronutrients collected for regular follow-up in TT1 and PKU patients in our hospital. The biochemical and micronutrient status of TT1 patients was largely comparable to that of PKU patients, as might be expected for the dietary treatment of PKU-nBH4 and TT1 is comparable. Especially in PKU patients, and to a lesser extent in TT1 patients, vitamin B12 concentrations were elevated, while vitamin D generally appeared to be lower than normal. In both diseases, both vitamin concentrations could to some extent be related to the natural protein intake and the tyrosine rather than the phenylalanine concentrations.

Before discussing our findings in more detail, some methodological issues need to be addressed. The group of TT1 patients in this study was relatively small compared to the group of PKU patients, which is due to the difference in incidence. This smaller sample size for the TT1 patients may have been insufficient to generate significant results. Since this is a retrospective study, we could only use data that had been requested by the clinician at the time of the outpatient visit. As a consequence, 
$17 \%$ of the blood values were missing. Dietary information was collected from patient files. However, these may not completely reflect the actual situation since patients may not always count their protein intake or have low treatment compliance [18,19]. It has been shown that PKU patients with high adherence to diet may have significant differences in biochemical markers compared to patients with low adherence to diet [5]. In our study, adherence could not be taken into account, and these possible differences could not be investigated. Furthermore, differences in blood concentrations for different amino acid mixtures could not be investigated because of the low number of patients per product. Lastly, some possibly relevant markers, such as blood concentrations of zinc and selenium [20], were not assessed, since these measurements are generally not included in regular follow-up in our center.

With regard to the findings, several studies have shown that PKU patients, both with and without BH4 may be at risk for developing vitamin B12 deficiency especially when adherence to diet is suboptimal $[4,6,9]$. For TT1 patients, evidence on possible B12 deficiencies is currently lacking. Remarkably, in our sample, vitamin B12 concentrations in TT1 and PKU patients were elevated rather than lowered. This could possibly be caused by a high dietary adherence and thus adequate intake, as also observed previously $[5,20]$. It should be noted, however, that MMA and total homocysteine are better markers of vitamin B12 status than B12 concentrations themselves, as a vitamin B12 deficiency can exist even when B12 concentrations are normal or high [4,21]. Since increased MMA and/or total homocysteine concentrations, suggesting a B12 deficiency, were found in a small number of patients (all having normal/high B12 concentrations), this may point toward a suboptimal B12 status in these patients. Vugteveen et al. suggested that vitamin B12 intake by amino acid mixture may not result in optimal absorption of vitamin B12 [21], which may in part explain our observed results.

Furthermore, our study suggests that a biochemical vitamin $\mathrm{D}$ deficiency may arise in approximately $25 \%-30 \%$ of the PKU patients, both PKU-nBH4 and PKU-BH4 patients (29\% and $24 \%$, respectively). A recent study by Kose and Arslan showed an even larger percentage of vitamin D deficiency in PKU patients in Turkey (53.6\%) [5]. However, they also showed a similar percentage of healthy controls (47.2\%) with this deficiency. In addition to this, a Dutch study investigating the prevalence of biochemical vitamin D deficiency in the normal population reported deficiencies in almost $60 \%$ of healthy individuals in the winter and roughly $30 \%$ in the summer [17]. These numbers considered, our PKU patients are doing relatively well. However, reference values in our hospital adhere to a lower limit of $50 \mathrm{nmol} / \mathrm{L}$, while it has been suggested that, optimally, values should be above $75 \mathrm{nmol} / \mathrm{L}$ [17]. The use of this favorable reference range would lead to the finding that vitamin D levels were suboptimal in $62.5 \%$ of our patients (including $7 / 12$ TT1 patients), even in some patients who were reported to use vitamin D supplements. PKU patients have also been shown to suffer from bone problems, such as reduced mineral bone density $[4,22]$. Although the pathogenesis of this has not been fully elucidated yet, we recommend, as a start, to optimize vitamin D concentrations in these patients. TT1 patients on the other hand, are known to develop vitamin D-resistant rickets, if untreated [23]. For TT1 patients the effect of vitamin D supplementation might, therefore, be different than the effect on PKU patients, but this needs further investigation. Both vitamin D and B12 concentrations were correlated to percentage of natural protein intake. The results suggest that higher intake of proteins from supplements result in higher vitamin concentrations. This may be due to the high vitamin content of amino acid supplements as also suggested previously [24]. Extra attention could, therefore, be paid to patients on a higher natural protein diet or patients who discontinued their amino acid supplements.

With tyrosine being the precursor of thyroxin, it can be hypothesized that altered tyrosine concentrations, as observed in PKU and TT1, may have an influence on thyroxin availability which can be assessed by measuring TSH levels. Our results did not show clear aberrations in TSH levels, which is in contrast with Sumanszki et al. who did observe lower TSH levels in adult PKU patients compared to controls [25]. Therefore, the possible effect of tyrosine (and phenylalanine) concentrations on thyroid function should be investigated in more detail.

Lastly, tyrosine concentrations appeared to be correlated to the vitamin B12 and vitamin D concentrations. For TT1, higher tyrosine levels (suggestive of less treatment adherence) indicated 
lower vitamin concentrations. Similarly, in PKU patients, higher tyrosine concentrations (suggestive of better treatment adherence) correlated with higher vitamin B12 and vitamin D. These findings underline the conclusion of Vugteveen et al. that the vitamin B12 concentrations may be related to the intake of amino acid supplements [21]. Literature describes negative correlations between vitamin B12 levels in PKU and phenylalanine levels, however, correlations with tyrosine have not been investigated previously $[5,6]$. Thus, although correlations with phenylalanine levels were not observed in our sample, both our results and the results from literature suggest a positive effect of treatment adherence on micronutrient status.

\section{Conclusions}

Diet therapy is important in the treatment of both PKU and TT1 patients. For many years, there have been concerns about nutritional deficiencies, however, the results of this study show that this is often not the case. The biomarkers of micronutrients of TT1 patients were largely comparable to those of PKU patients, and generally within the reference ranges. Vitamin B12 concentrations were high rather than low, while vitamin D concentrations were often below the reference range for which attention should be paid to the intake of protein supplements while specific supplementation can also be considered.

Supplementary Materials: The following are available online at http:/www.mdpi.com/2072-6643/11/9/2011/s1: Supplementary material S1: Micronutrients in the different amino acid mixtures used in our patient group.

Author Contributions: Conceptualization, K.v.V. and F.J.v.S.; Data curation, K.v.V. and I.L.R.; Formal analysis, K.v.V.; Investigation, K.v.V. and I.L.R.; Methodology, K.v.V., I.L.R., W.G.v.G., M.R.H.-F. and F.J.v.S.; Project administration, K.v.V.; Resources, K.v.V., C.M.A.L., B.H.R.W., M.M.v.d.K., M.R.H.-F. and F.J.v.S.; Supervision, F.J.v.S.; Validation, K.v.V.; Visualization, K.v.V., I.L.R., M.R.H.-F. and F.J.v.S.; Writing-original draft, K.v.V., I.L.R. and F.J.v.S.; Writing一review and editing, K.v.V., I.L.R., W.G.v.G., C.M.A.L., B.H.R.W., M.M.v.d.K., M.R.H.-F. and F.J.v.S.

Funding: This research received no external funding.

Conflicts of Interest: F.J. van Spronsen has received advisory board fees from SOBI, Merck Serono, Biomarin, Nutricia, APR, Arla Food int., and Promethera, research grants from SOBI, Merck Serono, Biomarin, Nutricia, Alexion, Codexis, NPKUA, ESPKU and the Tyrosinemia Foundation, honoraria as consultant for Merck Serono, Biomarin, Nutricia, and APR, and honoraria as speaker for Merck Serono, Biomarin, Nutricia, Vitaflo and MendeliKABS. C.M.A. Lubout has received a speaker fee from the Recordati Rare Disease Foundation. M.M. van der Klauw received a fee from Biomarin for preparation of a study. All other authors had no conflicts of interest to declare.

\section{References}

1. Blau, N.; van Spronsen, F.J.; Levy, H.L. Phenylketonuria. Lancet 2010, 376, 1417-1427. [CrossRef]

2. Van Spronsen, F.J.; van Wegberg, A.M.; Ahring, K.; Bélanger-Quintana, A.; Blau, N.; Bosch, A.M.; Burlina, A.; Campistol, J.; Feillet, F.; Giżewska, M.; et al. Key European Guidelines for the Diagnosis and Management of Patients with Phenylketonuria. Lancet Diabet. Endocrinol. 2017, 5, 743-756. [CrossRef]

3. Hennermann, J.B.; Bührer, C.; Blau, N.; Vetter, B.; Mönch, E. Long-Term Treatment with Tetrahydrobiopterin Increases Phenylalanine Tolerance in Children with Severe Phenotype of Phenylketonuria. Mol. Genet. Metab. 2005, 86 (Suppl. S1), 86-90. [CrossRef] [PubMed]

4. Robert, M.; Rocha, J.C.; van Rijn, M.; Ahring, K.; Bélanger-Quintana, A.; MacDonald, A.; Dokoupil, K.; Gokmen Ozel, H.; Lammardo, A.M.; Goyens, P.; et al. Micronutrient Status in Phenylketonuria. Mol. Genet. Metab. 2013, 110 (Suppl. S6). [CrossRef] [PubMed]

5. Kose, E.; Arslan, N. Vitamin/Mineral and Micronutrient Status in Patients with Classical Phenylketonuria. Clin. Nutr. 2019, 38, 197-203. [CrossRef] [PubMed]

6. Crujeiras, V.; Aldámiz-Echevarría, L.; Dalmau, J.; Vitoria, I.; Andrade, F.; Roca, I.; Leis, R.; FernandezMarmiesse, A.; Couce, M.L. Vitamin and Mineral Status in Patients with Hyperphenylalaninemia. Mol. Genet. Metab. 2015, 115, 145-150. [CrossRef] [PubMed] 
7. Thiele, A.G.; Weigel, J.F.; Ziesch, B.; Rohde, C.; Mütze, U.; Ceglarek, U.; Thiery, J.; Müller, A.S.; Kiess, W.; Beblo, S. Nutritional Changes and Micronutrient Supply in Patients with Phenylketonuria Under Therapy with Tetrahydrobiopterin (BH(4)). JIMD Rep. 2013, 9, 31-40.

8. Rohde, C.; von Teeffelen-Heithoff, A.; Thiele, A.G.; Arelin, M.; Mütze, U.; Kiener, C.; Gerloff, J.; Baerwald, C.; Schultz, S.; Heller, C.; et al. PKU Patients on a Relaxed Diet may be at Risk for Micronutrient Deficiencies. Eur. J. Clin. Nutr. 2014, 68, 119-124. [CrossRef]

9. Brantley, K.D.; Douglas, T.D.; Singh, R.H. One-Year Follow-Up of B Vitamin and Iron Status in Patients with Phenylketonuria Provided Tetrahydrobiopterin (BH4). Orphanet. J. Rare Dis. 2018, 13, 192. [CrossRef]

10. De Laet, C.; Dionisi-Vici, C.; Leonard, J.V.; McKiernan, P.; Mitchell, G.; Monti, L.; de Baulny, H.O.; Pintos-Morell, G.; Spiekerkötter, U. Recommendations for the Management of Tyrosinaemia Type 1. Orphanet. J. Rare Dis. 2013, 8, 8. [CrossRef]

11. Lindstedt, S.; Holme, E.; Lock, E.A.; Hjalmarson, O.; Strandvik, B. Treatment of Hereditary Tyrosinaemia Type I by Inhibition of 4-Hydroxyphenylpyruvate Dioxygenase. Lancet 1992, 340, 813-817. [CrossRef]

12. Bendadi, F.; de Koning, T.J.; Visser, G.; Prinsen, H.C.; de Sain, M.G.; Verhoeven-Duif, N.; Sinnema, G.; van Spronsen, F.J.; van Hasselt, P.M. Impaired Cognitive Functioning in Patients with Tyrosinemia Type I Receiving Nitisinone. J. Pediatr. 2014, 164, 398-401. [CrossRef] [PubMed]

13. Van Ginkel, W.G.; Jahja, R.; Huijbregts, S.C.J.; Daly, A.; MacDonald, A.; De Laet, C.; Cassiman, D.; Eyskens, F.; Körver-Keularts, I.M.L.W.; Goyens, P.J.; et al. Neurocognitive Outcome in Tyrosinemia Type 1 Patients Compared to Healthy Controls. Orphanet. J. Rare Dis. 2016, 11, 87. [CrossRef] [PubMed]

14. García, M.I.; de la Parra, A.; Arias, C.; Arredondo, M.; Cabello, J.F. Long-Term Cognitive Functioning in Individuals with Tyrosinemia Type 1 Treated with Nitisinone and Protein-Restricted Diet. Mol. Genet. Metab. Rep. 2017, 11, 12-16. [CrossRef] [PubMed]

15. De Laet, C.; Munoz, V.T.; Jaeken, J.; François, B.; Carton, D.; Sokal, E.M.; Dan, B.; Goyens, P.J. Neuropsychological Outcome of NTBC-Treated Patients with Tyrosinaemia Type 1. Dev. Med. Child Neurol. 2011, 53, 962-964. [CrossRef]

16. Thimm, E.; Richter-Werkle, R.; Kamp, G.; Molke, B.; Herebian, D.; Klee, D.; Mayatepek, E.; Spiekerkoetter, U. Neurocognitive Outcome in Patients with Hypertyrosinemia Type I After Long-Term Treatment with NTBC. J. Inherit. Metab. Dis. 2012, 35, 263-268. [CrossRef]

17. Boonman-de Winter, L.J.M.; Albersen, A.; Mohrmann, K.; Bakx-van Baal Carla MA, C.; Meijer Timmerman Thijssen Dirk, W.; Bressers, J.P. [High Prevalence of Vitamin D Deficiency in the South-West Netherlands]. Ned Tijdschr Geneeskd 2015, 159, A8167.

18. MaCdonald, A.; van Rijn, M.; Feillet, F.; Lund, A.M.; Bernstein, L.; Bosch, A.M.; Gizewska, M.; van Spronsen, F.J. Adherence Issues in Inherited Metabolic Disorders Treated by Low Natural Protein Diets. Ann. Nutr. Metab. 2012, 61, 289-295. [CrossRef]

19. Malik, S.; NiMhurchadha, S.; Jackson, C.; Eliasson, L.; Weinman, J.; Roche, S.; Walter, J. Treatment Adherence in Type 1 Hereditary Tyrosinaemia (HT1): A Mixed-Method Investigation into the Beliefs, Attitudes and Behaviour of Adolescent Patients, their Families and their Health-Care Team. JIMD Rep. 2015, 18, 13-22.

20. Demirdas, S.; van Spronsen, F.J.; Hollak, C.E.M.; van der Lee, J.H.; Bisschop, P.H.; Vaz, F.M.; Ter Horst, N.M.; Rubio-Gozalbo, M.E.; Bosch, A.M. Micronutrients, Essential Fatty Acids and Bone Health in Phenylketonuria. Ann. Nutr. Metab. 2017, 70, 111-121. [CrossRef]

21. Vugteveen, I.; Hoeksma, M.; Monsen, A.B.; Fokkema, M.R.; Reijngoud, D.; van Rijn, M.; van Spronsen, F.J. Serum Vitamin B12 Concentrations within Reference Values do Not Exclude Functional Vitamin B12 Deficiency in PKU Patients of various Ages. Mol. Genet. Metab. 2011, 102, 13-17. [CrossRef] [PubMed]

22. Demirdas, S.; Coakley, K.E.; Bisschop, P.H.; Hollak, C.E.M.; Bosch, A.M.; Singh, R.H. Bone Health in Phenylketonuria: A Systematic Review and Meta-Analysis. Orphanet. J. Rare Dis. 2015, 10, 17. [CrossRef] [PubMed]

23. Gentz, J.; Jagenburg, R.; Zetterstroem, R. Tyrosinemia. J. Pediatr. 1965, 66, 670-696. [CrossRef] 
24. MacDonald, A.; Rocha, J.C.; van Rijn, M.; Feillet, F. Nutrition in Phenylketonuria. Mol. Genet. Metab. 2011, 104 (Suppl. S10). [CrossRef] [PubMed]

25. Sumanszki, C.; Kiss, E.; Simon, E.; Galgoczi, E.; Soos, A.; Patocs, A.; Kovacs, B.; Nagy, E.V.; Reismann, P. The Association of Therapy Adherence and Thyroid Function in Adult Patients with Phenylketonuria. Ann. Nutr. Metab. 2019, 1-8. [CrossRef] [PubMed]

(C) 2019 by the authors. Licensee MDPI, Basel, Switzerland. This article is an open access article distributed under the terms and conditions of the Creative Commons Attribution (CC BY) license (http://creativecommons.org/licenses/by/4.0/). 